\title{
Exploration of Product Design Mode under Low-carbon Concept Ying Gao
}

\author{
Wuhan Polytechnic, Wuhan Hubei,430070,China
}

\begin{abstract}
Key words: Low carbon concept, Product design, Mode.
\end{abstract}
\begin{abstract}
People's attention to low carbon concept improves gradually. In particular, the concept of low carbon and environmental protection starts to fuse in product design so as to improve environmental protection idea of products, and really achieve effective product design and the original intention of project design. This also proposes new requirements and challenges of product designers. Designers need to think over and actively explore how to effectively fuse low carbon and environmental protection concept in actual operation process in practice. This paper simply analyzes the concept of low carbon and environmental protection and deeply discusses the era background of product design under low carbon concept and product design mode. This paper aims to offer effective project suggestions on designers and really drive sustainable development of product design project.
\end{abstract}

\section{Connotation of low carbon concept}

The concept of low carbon and environmental protection has become popular in recent years. It mainly focuses on environmental protection mechanism and environmental protection operation measures. More greening and visual behaviors are established while the concept of environmental protection is guaranteed. Low carbon means the quantity of greenhouse gases emitted in the air is small in actual work and production, and the overall behavior has such traits as low energy consumption and low carbon. It operates scientific development project handling mechanism. An British scholar proposed the concept of low carbon first. The concept of low carbon was established for environmental protection in 2003 energy white paper. People are required to enhance cognition of environmental protection and create project operation structure with lower energy consumption. Besides, people are required to further enhance their environmental protection awareness, really reduce emission of coal and petroleum and achieve a win-win situation of economic growth and environmental protection. In addition, environmental protection campaign also rises in the world in the process of proposing the concept of low carbon. The concept of low carbon penetrates not just in industrial projects, but also in all aspects in life. Low-carbon footprint, low-carbon life structure, low-carbon economy and low-carbon technology develop continuously. When people conduct low-carbon technology of lie behaviors, corresponding work behaviors also change gradually. The research, development and application projects for energy saving materials develop continuously. From the perspective of design science, design activity based on the concept of low carbon and environmental protection can not just effectively reduce carbon emission, but also guarantee effective evasion of environmental threat brought by greenhouse gases. The implementation of concept of low carbon and environmental protection in product design can really achieve development of green and environmental protection design and continue the idea of sustainable development ${ }^{[1]}$.

\section{Era background of product design under the concept of low carbon}

\section{New balance between product and designer under the concept of low carbon}

In low carbon idea, the design mode aims to acquire better appreciation value and use value. Thus, there are not too many restrictions on materials used. Especially in 1930, overuse atmosphere started to rise in western countries. To gain more commercial benefits and values, product manufacturers and designers started to design rare and exaggerated products in quantity, and made the products bought by consumers lose fashion and be eliminated in a short time by human means. Excessive design and 
excessive consumption resulted in the sharp increase in ecological environment pressure. People were faced with unprecedented resource exhaustion problem in actual life. This not merely caused the attention of the whole world. Besides, people started to realize the importance of environmental protection and resource maintenance. Western countries began to gradually change design idea and design thought. In order to further optimize handling mechanism of corresponding projects, planned saving and planned waste restriction started to be implemented. Corresponding environmental-friendly design became the new design thought of mainstream designers. Many people would also adopt corresponding environmental protection idea in small-scale product design. The society continuously urged the people to use products to the largest extent, and carry out secondary development of products. Green design, lo-w-carbon and environment-friendly products gradually entered the market. People started to carry design operation in the capacity of social protector in the design process ${ }^{[2]}$.

Green design requires designers carrying out effective project consideration of environment in each design process, making sure decision making and design behaviors have certain value of environmental protection and guaranteeing consideration of recycling factor in design process so as to really achieve recycling and reutilization. People apply their cognition for the concept of low carbon and environmental protection to carry out design and achieve novel modeling of environmental protection, structural and functional low carbon and environmental protection. This is a thorough consciousness reform and also the game between product designers and environmental protection idea. Designers should focus on the relationship between products and consumers in the design process, and analyze consumers' consumption purpose in detail. Thus, environmental-friendly design has very profound social connotation in the design field ${ }^{[3]}$. In actual management process, designers should improve their sense of responsibility, effectively handle the relationship between human and nature and guarantee fusion of products and environmental protection idea. Meanwhile, designers should effectively operate corresponding design requirements and norms, continuously launch new products in the project design process, really positively guide consumers and effectively promote positive development of purchasing sense and purchasing behavior through the designed products. In other words, designers bear the responsibility of balance and establish the optimal balance between consumers' consumption idea and actual environmental requirement.

\section{New balance of product and product modeling design under the concept of low carbon}

In product design and production process, designers should establish effective management and control mechanism for different problems. For design modeling, more optimized handling measures should be taken. Product design process is a process of information collection and optimal display. Designers utilize basic lines, symbols and corresponding colors for project and product design, and make sure they have certain use value and structural harmony. The process of presenting the plan and imagination through specific carriers is the design process. Moreover, in the process of studying actual design project, designers will find that in the design process, designers should not just carry out concentrated processing and analysis of product function, structure and materials, but also plan and integrate processing technology of deigned products so as to really achieve bearing function and inheritance effect of products. In product design process, designers should fully fuse the concept of low carbon and environmental protection in the design project, guarantee centralized management and control of low-carbon and environmental protection in the whole product life cycle and achieve upgrade of environmental protection materials. Especially in actual product design process, basic structure of products should be valued, and actual modeling of products' should be detailed to make sure the products comply with actual demand in terms of both appearance and inherent use value. It is required to start from the concept of low carbon and environmental protection, achieve further optimization of product modeling deign, establish original design, promote use effect of product materials and guarantee effective extension of user cycle.

In practical design process, designers should utilize effective color and modeling language to convey environmental protection idea to consumers so as to generate positive influence on consumers 
and guarantee upgrade of environmental protection effect of product design and product value. In practical modeling design process, designers may utilize corresponding design means and design modes to guarantee environmental protection upgrade of product modeling and achieve new balance of products and product modeling design under the concept of low carbon.

\section{Analysis of product design mode under the concept of low carbon}

\section{Design mode of quantitative reduction}

The application of low carbon and environmental protection concept in practical design project requires designers really realizing visual quantitative reduction in practical design and application process so as to promote upgrade of project design idea. The fundamental requirements of green design project include environmental protection and reduction, such as effective reduction of materials, waste and space. In one word, production circulation and energy conservation of environmental protection are guaranteed through material and volume reduction so as to achieve optimization and rational allocation of basic energy ${ }^{[4]}$. Meanwhile, it is required to optimally design structure and state, reduce excessive decoration and complex design, utilize the fewest resources and simplest materials to ensure fluency of overall design modeling, effectively improve overall structure design and optimize the operation mechanism.

\section{Design mode of functional modularization}

In product design process, various design elements should be integrated so as to make each major factor can be united effectively and form effective sub-system. Each sub-system will form a new system in element combination process. In other words, functional modularization in design behavior aims to effectively integrate original factors so as to form the substances with new significance and idea which can present different property and function in actual use process. To apply the concept of low carbon and environmental protection in functional modularization design, the fewest materials should be used to do the optimal project. Meanwhile, diversified combination and modularized product upgrade should be conducted actively. In the design process, designers should effectively comtrol energy consumption in product production process in order to achieve efficient combination of functionalization, low carbon and environmental protection. Meanwhile, the optimal functional module should be established to meet individualized design demand and achieve optimal operation of freely combined projects ${ }^{[5]}$.

\section{Design mode of behavioral restriction}

To operate the concept of low carbon and environmental protection in design behavior, designers' consciousness and idea should improve. Besides, design mode and method should be upgraded. Behavioral restriction design mode is widely applied. Design behavior is utilized to reduce carbon emission. For consumers, certain waste will inevitably occur due to personal habits in using the corresponding products. Behavioral restriction measure is corresponding design behavior and measure for such problem. It guarantees indirect control of consumers' waste behavior in design idea and design structure and tries to reduce consumers' waste behaviors. Such design structure can gain significant effect un actual operation process, and guarantees generation of certain restriction for consumers' behaviors. In practical design process, behavioral restriction operation mechanism mainly involves two aspects. On the one hand, designers give products special effect in the design process, and the main operation is achieved in the research and development process; on the other hand, concentrated control and restriction of design form are conducted to effectively guide consumers to reduce corresponding use behavior. Prominent cases include energy saving lamp and induction-type faucet. These are behavior guidance for consumers through design philosophy in actual design process. 


\section{Design mode of concept guidance}

In product design process, concept guidance design mode refers to guidance of consumers' ideology by designed ping products. The concrete carriers are used for information transfer. People's behaviors and environmental protection concept are controlled and guided from details. Integration of low carbon and environmental protection concept in practical design project can effectively promote handling link of overall project and awaken people's environmental awareness so as to establish conscious environmental protection behavior, really achieve normal development of environmental protection and make sure people form the idea of environmental protection and low carbon life in practical production and life. In practical product design process, concept guidance design mode mainly involves two aspects. On the one hand, graphic design guidance. Product surface design and corresponding photocopy decoration are utilized for transportation of environmental protection concept, including green and environmental protection marks, green and environmental protection slogans etc.; on the other hand, three-dimensional design guidance. The overall design structure is three-dimensional, and green and environmental protection concept is integrated in the overall project design. Environmental protection publicity aims to further make designers and consumers closer.

\section{Design mode of waste material recycling}

In practical product design process, optimized waste recovery has become the operation principle of the whole design circle, and some designers carry out secondary design and creation by waste products. They utilize concentrated recovery and collection of waste and old materials, operate effective project redesign and transform waste into the resources with design characteristics. This challenges designers' professional ability. It is required to guarantee optimal utilization of recovered materials of wastes products and make sure the designed products can be presented with an acceptable form.

\section{Conclusion}

In one word, in order to integrate low carbon and environmental protection concept in product design project, designers need to get rid of commercial purpose and carry out product design from long-term view so as to really achieve harmony between man and nature and drive sustainable development of integration of product design and low carbon idea.

\section{Acknowledgement}

This paper is subsidized by the following topics:

1. University-level topic: study on university-enterprise deep cooperation teaching mode for product design specialty courses, No.: 2013YJ792; person in charge: Zou Xianxiang

2. Title of topic: teaching resource library course project package of art design specialty (industrial design) in national higher vocational education, No.: 2013HR829; person in charge: Duan Linjie 3. Title of topic: special case development of teaching resource library for art design specialty (industrial design) in national higher vocational education, No.: 2013HR829; person in charge: Duan Linjie

4. Title of topic: professional teaching resource library construction of higher vocational education subproject construction of core courses and product form design basis of art design and media, No.: 2012HK644; person in charge: Duan Linjie

\section{References}

[1] Wang Jiping, Li Minmin, Study on low-carbon national tourism product design and development - case study of Xijiang Qianhu Miao Village in Guizhou, Research On Development, 2013,13(02):59-62. 
[2] Fang Yan, Starting point of modern product design - green design and low carbon, Art Panorama, 2011,17(06):129-129.

[3] Liu Xinxiong, Chen Wenhui, Application of minimalism idea in modern industrial design, Collected papers of academic conference of industrial design and collaborative innovation - the 20th nationwide academic annual conference of industrial design. 2015:181-182.

[4] Li Xinlu, Thought on low carbon and green ecological product design, Collected papers of academic conference of 2013 international industrial design - the 15th nationwide industrial design, 2013:115-116.

[5] Zhou Jun, Zhong Haiyan, Huang Peijin et al., sustainable design of natural materials under the concept of “turning “waste” into wealth”, Beauty \& Time (I), 2016,18(02):90-92. 